\title{
Protection of neurons in the retinal ganglion cell layer against excitotoxicity by the $\mathrm{N}$-acylethanolamine, $\mathrm{N}$-linoleoylethanolamine
}

This article was published in the following Dove Press journal:

Clinical Ophthalmology

22 April $201 \mathrm{I}$

Number of times this article has been viewed

\section{R. Scott Duncan ${ }^{1, *}$ \\ Hua Xin $^{1, *}$ \\ Daryl L Goad' \\ Kent D Chapman ${ }^{2,3}$ \\ Peter Koulen ${ }^{1,3}$ \\ 'Vision Research Center and Departments of Ophthalmology and Basic Medical Science, School of Medicine, University of Missouri, Kansas City, MO, USA; ${ }^{2}$ Department of Biological Sciences, University of North Texas, Denton, TX, USA; ${ }^{3}$ Center for Plant Lipid Research, University of North Texas, Denton, TX, USA \\ *Authors contributed equally}

Correspondence: Peter Koulen

Vision Research Center and Departments of Ophthalmology and Basic Medical Science, School of Medicine, University of Missouri - Kansas City,

24I I Holmes St, Kansas City, MO 64108, USA

Tel + I 8164041834

Fax +18164041825

Email koulenp@umkc.edu
Abstract: Retinal ganglion cell (RGC) death is a hallmark of neurodegenerative diseases and disease processes of the eye, including glaucoma. The protection of RGCs has been an important strategy for combating glaucoma, but little clinical success has been reported to date. One pathophysiological consequence of glaucoma is excessive extracellular glutamate subsequently leading to excitotoxicity in the retina. Endocannabinoids, such as the $N$-acylethanolamine (NAE), arachidonylethanolamine (NAE 20:4), exhibit neuroprotective properties in some models of neurodegenerative disease. The majority of NAEs, however, are not cannabinoids, and their physiological function is not clear. Here, we determined whether the noncannabinoid NAE, linoleoylethanolamine (NAE18:2), protects neurons in the RGC layer against glutamate excitotoxicity in ex-vivo retina cultures. Using a terminal deoxynucleotidyl transferase-mediated dUTP ( 2 '-deoxyuridine 5 '-triphosphate) nick-end labeling (TUNEL) assay, we determined that NAE18:2 reduces the number of apoptotic RGC layer neurons in response to glutamate and conclude that NAE18:2 is a neuroprotective compound with potential for treating glaucomatous retinopathy.

Keywords: neuroprotection, glutamate, calcium signaling, immunocytochemistry, eye, vision, glaucoma.

The most widespread form of glaucoma, primary open-angle glaucoma, is characterized by increased intraocular pressure (IOP), optic disc cupping, retinal ganglion cell (RGC) death and visual loss. ${ }^{1}$ Glaucoma is often preceded by elevated IOP followed by optic nerve damage, glial activation, oxidative stress, and excitotoxicity. ${ }^{2-6}$ Several studies have revealed that glutamate-induced RGC excitotoxicity occurs in animal models. ${ }^{5,7-11}$ As a result, RGC neuroprotection against excitotoxicity and other pathophysiological processes in glaucoma is considered a viable therapeutic strategy for glaucoma. ${ }^{12,13}$ Inhibition of NMDA (N-methyl-D-aspartate) receptors with the selective antagonists MK-801 or memantine can reduce excitotoxic RGC death in animal models of glaucoma..$^{5,8,10,11,14}$ Previous work from our laboratory reveals that RGCs in postnatal mouse retinal explant cultures are susceptible to excitotoxicity. ${ }^{15}$

$\mathrm{N}$-acylethanolamides (NAEs) are lipid-signaling molecules involved in numerous physiological functions in mammals, including cytoprotection. Some NAEs, and their precursors, are produced in rat brain in response to excitotoxicity, ischemia, and stroke, ${ }^{16-21}$ suggesting their possible role in cytoprotection.

Unlike the well characterized endocannabinoid NAE 20:4, the molecular target of some NAE species, such as palmitoylethanolamine (NAE 16:0) and NAE 18:2, is not known. Strong evidence for noncannabinoid NAE-mediated cytoprotection comes 
from multiple studies. For example, NAE 16:0 protects the hippocampal cell line, HT22, from oxidative stress, and it activates the neuroprotective Akt and ERK1/2 pathways. ${ }^{22}$ NAE16:0 administration prior to or after middle cerebral artery occlusion in rats leads to significant reduction in stroke severity. ${ }^{23}$

Many different NAEs are produced in the retina. ${ }^{24}$ In addition, receptors for NAEs and enzymes involved in NAE metabolism are expressed in the retina, suggesting that NAEs may provide protection of retinal neurons in diseases of the eye. ${ }^{25-30}$ For example, activation of cannabinoid receptor type 1 (CB1) with a synthetic $\mathrm{CB} 1$ receptor agonist protects retina neurons from excitotoxicity and oxidative stress. ${ }^{31}$

Here, we report that the naturally occurring NAE 18:2 protects neurons in the RGC layer against glutamate excitotoxicity in organotypic retina cultures. We determined that NAE 18:2 reduced the number of apoptotic RGC layer neurons in response to glutamate by TUNEL (terminal deoxynucleotidyl transferase-mediated dUTP [2'-deoxyuridine 5 '-triphosphate] nick-end labeling) histochemistry, indicating that NAE 18:2 may be a neuroprotective compound with potential for treating acute and chronic RGC damage as seen in retinal ischemia and glaucomatous retinopathy, respectively.

\section{Materials and methods}

\section{Animals and tissue culture}

All animal procedures were conducted in accordance with National Institutes of Health (NIH) and institutional regulations on Care and Use of Laboratory Animals. Whole retinas were isolated from $\mathrm{C} 57 \mathrm{BL} / 6$ mice and maintained as organotypic cultures as described elsewhere. ${ }^{15}$ In brief, C57BL/6 mice (P10-P14) were euthanized by overexposure to $\mathrm{CO}_{2}$ and decapitated. Freshly enucleated eyes were rinsed in cold Hank's Balanced Salt Solution (HBSS) (HyClone Inc, Logan, UT) under sterile conditions. The retinas were removed from the eyes, and incisions were introduced in the shape of a Maltese cross to flatten the retina tissue. Retinas were placed onto poly-D-lysine/laminin-coated glass coverslips (BD Bioscience, Bedford, MA) with the ganglion cell layer facing the coverslip. The retina was permitted to attach to the coverslip for 30 minutes at room temperature in $20 \mu \mathrm{L}$ of culture medium (Neurobasal-A Medium, Gibco, Carlsbad, CA with 2\% DHS [donor horse sera], B27 supplement, and penicillin-streptomycin-fungizone). Retinas were incubated at $37^{\circ} \mathrm{C}$ with $5 \% \mathrm{CO}_{2}$ for 7 days in vitro, and culture media was replaced every other day.

\section{Experimental groups}

Retinas from C57Bl/6 mice were treated with NAE 18:2 (or ethanol vehicle) over a range of physiologically relevant concentrations $(20-120 \mu \mathrm{M})$ for 6 hours prior to addition of and during exposure to $100 \mu \mathrm{M}$ glutamate for 24 hours (30 hour NAE 18:2 exposure total). The 6-hour NAE 18:2 pretreatment was selected because previous studies with other NAEs indicate that a 6 -hour pretreatment protects a neuronal cell line against oxidative stress. ${ }^{22}$ Additionally, retinas received NAE 18:2 treatment (or ethanol vehicle) 24 hours prior to addition of and during exposure to a 24-hour glutamate treatment or at the same time as glutamate treatment for 24 hours (co-treatment paradigm; 48-hour NAE 18:2 exposure total) in order to determine a therapeutic window.

\section{Cell viability measurements}

Identification of neurons in the RGC layer in explants was determined using cell specific immunohistochemistry, and loss of neurons in the RGC layer was assessed using the TUNEL assay as described elsewhere. ${ }^{15,32}$ Retinas attached to coverslips were fixed in 4\% paraformaldehyde and subjected to the TUNEL assay to detect apoptotic cells as described elsewhere. ${ }^{15}$ Coverslips were mounted onto microscope slides using Prolong Gold antifade mounting medium containing DAPI (4',6-diamidino-2-phenylindole) (Molecular Probes, Eugene, OR) to visualize nuclei. Fluorescent and differential interference contrast (DIC) images were acquired with an epifluorescence microscope (Olympus IX70, Japan) using digital microphotography (Hamamatsu, Japan), and analysis of images was conducted using SimplePCI (Compix Inc, Image Systems, Sewickley, PA). Images from four $8000 \mu \mathrm{M}^{2}$ regions from each condition were used for analysis. Background fluorescence of vehicle control images was subtracted from micrographs to better visualize TUNEL fluorescence. TUNEL-positive RGCs were manually counted in each micrograph, and data were graphed with standard errors in Microsoft Excel. Statistical analysis between treatment groups was determined using a one-way analysis of variance (GraphPad Prism 5.01).

\section{Results}

\section{Evaluation of glutamate and NAE I8:2 on the viability of RGC layer neurons in retinal explant cultures}

To determine whether NAE 18:2 alone had an effect on the viability of neurons in the RGC layer, retina explants were treated with NAE 18:2 (or ethanol vehicle) for 24 hours followed by TUNEL assay to detect apoptosis (Figure 1). 
Exposure of explants to NAE 18:2 did not result in apoptotic retinal cells compared with the vehicle control (Figure 1). To verify glutamate sensitivity of RGC layer neurons, explants were exposed to glutamate $(100 \mu \mathrm{M})$ for 24 hours. Glutamate exposure led to significant RGC apoptosis as determined by the TUNEL assay (Figure 1).

\section{NAE 18:2 protects RGC layer neurons against glutamate-induced excitotoxicity}

Retinas were treated 6 hours prior to glutamate insult with 20-120 $\mu \mathrm{M}$ NAE 18:2 (along with vehicle) to determine

A

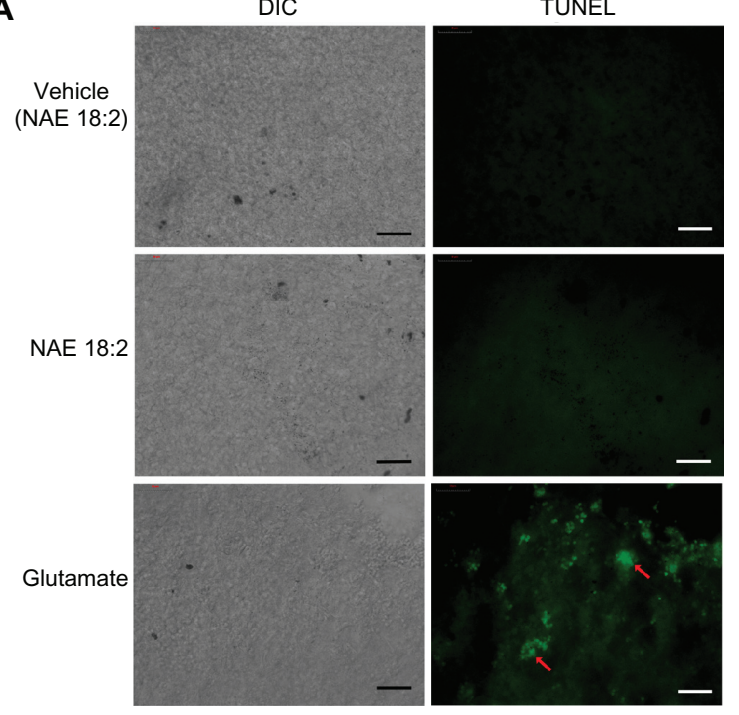

B

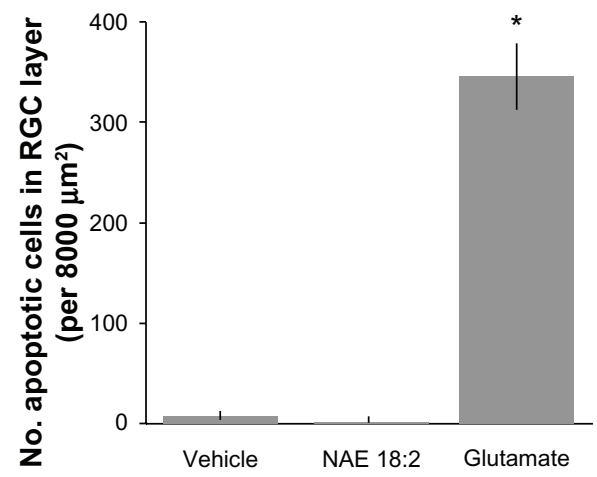

Figure I Neurons in the RGC layer are sensitive to glutamate excitotoxicity A) Exposure of retinas to $40 \mu \mathrm{M}$ NAE 18:2 or ethanol vehicle does not affect viability of neurons in the RGC layer. Glutamate (100 $\mu \mathrm{M})$ exposure, however, causes apoptotic cell death in the RGC layer of retina explants (red arrows). B) Quantitative summary data revealing the lack of toxicity of NAE I8:2 or its vehicle as well as the degree of cell death in the RGC layer measured as the number of TUNEL-positive cells in retinas exposed to glutamate. RGCs were identified by Thy 1.2 and neurofilament-68 kDa immunoreactivity and location..$^{15,32}$

Notes: Scale bar: $50 \mu \mathrm{M}$. *denotes $P<0.05$, as determined with a one-way analysis of variance test.

Abbreviations: DIC, differential interference contrast; NAE, $\mathrm{N}$-acylethanolamide; RGC, retinal ganglion cell; TUNEL, terminal deoxynucleotidyl transferase-mediated dUTP ( 2 '-deoxyuridine $5^{\prime}$-triphosphate) nick-end labeling - green fluorescence. whether physiological concentrations affect neuronal viability. Previous studies with a structurally similar NAE reveal that a 6-hour preincubation is neuroprotective, thus providing a rationale for a 6-hour NAE 18:2 preincubation. ${ }^{22}$ Preincubation with NAE 18:2, at 6 hours prior to glutamate exposure resulted in a dose-dependent decrease in the number of TUNEL-labeled (apoptotic) RGCs (Figure 2). Retinas exposed to NAE 18:2 at concentrations above $40 \mu \mathrm{M}$ exhibit dramatically reduced TUNEL labeling of neurons in the RGC layer (Figure 2). An NAE 18:2 concentration of $40 \mu \mathrm{M}$ approximates a high physiological concentration, thus avoiding the need for potentially toxic supra-physiological exposures. These results suggest that 6-hour NAE 18:2 pretreatment dose-dependently increases neuronal viability after $100 \mu \mathrm{M}$ glutamate-mediated induction of apoptosis of neurons in the RGC layer.

\section{NAE 18:2 preincubation is critical for its neuroprotective effect}

To further determine the requirement for NAE 18:2 preincubation in RGC layer neuroprotection, retina explants were pretreated with $40 \mu \mathrm{M}$ NAE 18:2 at 24 hours prior to and subsequently during glutamate exposure (24-hour pretreatment) or administered at the same time as glutamate treatment (no preincubation). Retina explants pretreated with NAE 18:2 for 24 hours prior to glutamate insult exhibited significantly reduced RGC apoptosis, whereas retinas co-treated with NAE 18:2 and glutamate exhibited no protection of neurons in the RGC layer against glutamate-induced apoptosis (Figure 3). There was, however, a trend toward a reduction in neuronal apoptotis when retinas were co-treated with $80 \mu \mathrm{M}$ NAE 18:2 and glutamate (Figure 3B).

\section{Discussion}

Here, we show that NAE 18:2 protects RGC layer neurons from glutamate-induced apoptosis in retinal explant cultures. We determined that NAE 18:2 treatment must precede glutamate exposure to elicit its neuroprotective effect. The highly significant, dose-dependent reduction of glutamate-induced death of RGC layer neurons by treatment with NAE 18:2 reveals a neuroprotective function for NAEs that do not bind to cannabinoid receptors. These results provide a rationale for the use of NAEs as potential therapeutic compounds in acute and chronic neurodegenerative diseases of the retina. Whether or not excitotoxic RGC death occurs in glaucoma has been controversial. ${ }^{33,34}$ Here, we observed RGC layer neuron death at glutamate concentrations consistent with activation of ionotropic glutamate receptors and not delayed oxidative glutamate toxicity due to glutathione depletion. 
A

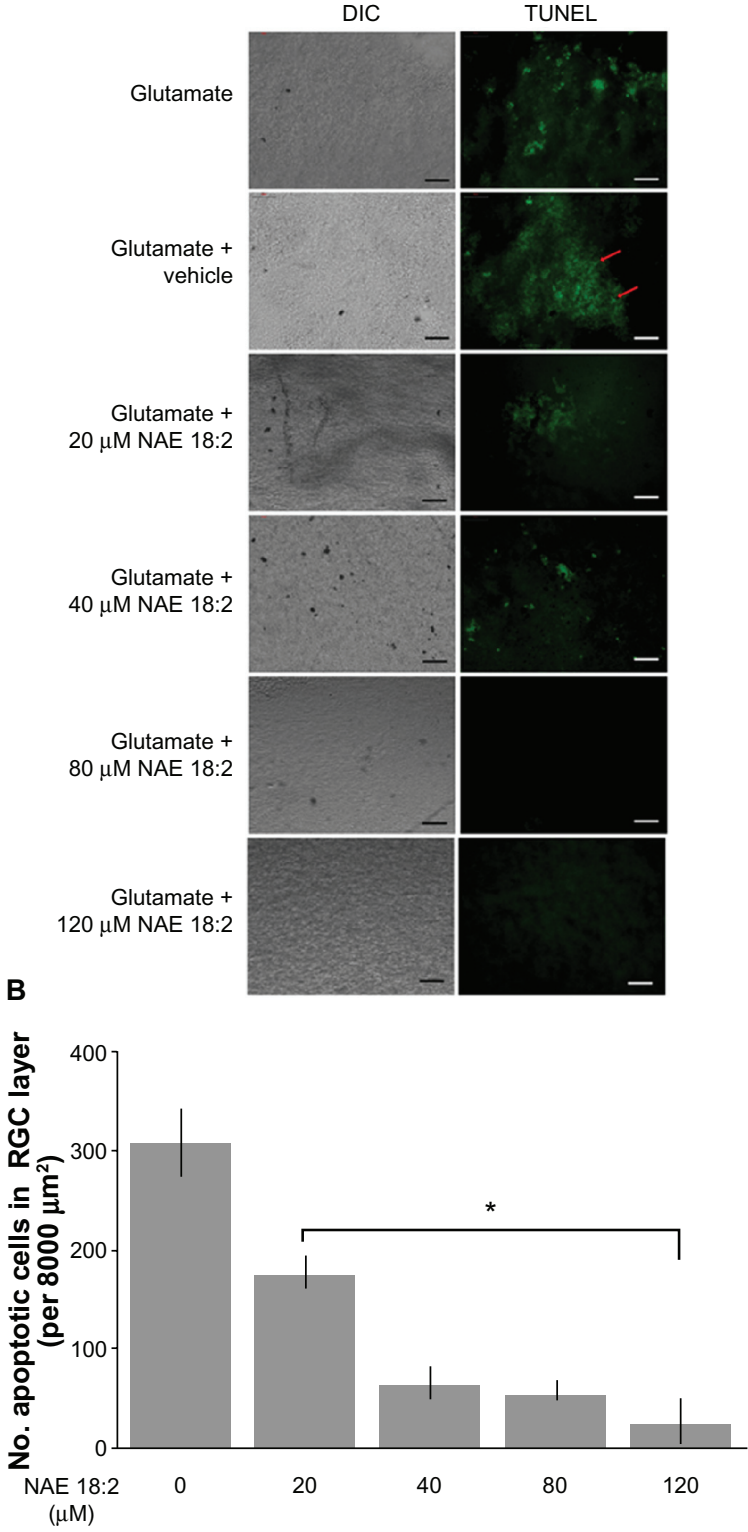

Figure 2 NAE 18:2 protects RGC layer neurons from glutamate excitotoxicity. A) Exposure of retinas to $100 \mu \mathrm{M}$ glutamate resulted in a dramatic increase in RGC layer neuron death (red arrows). Preincubation of retinas with NAE I8:2 for 6 hours prior to glutamate exposure resulted in a dose-dependent decrease in the number apoptotic, TUNEL-positive RGC layer neurons, with high physiological concentrations reducing the number of apoptotic neurons. RGCs were identified by Thy 1.2 immunoreactivity and location. ${ }^{15,32}$ B) Quantitative summary data for the NAE 18:2-mediated neuroprotection from glutamate toxicity as measured by TUNEL histochemistry.

Notes: *denotes $P<0.05$, as determined by a one-way analysis of variance test. Scale bar: $50 \mu \mathrm{M}$

Abbreviations: DIC, differential interference contrast; NAE, $\mathrm{N}$-acylethanolamide; RGC, retinal ganglion cell; TUNEL, terminal deoxynucleotidyl transferase-mediated dUTP (2'-deoxyuridine 5'-triphosphate) nick-end labeling - green fluorescence.

NAEs, as well as the receptors and enzymes involved in NAE function, are present in the retina. ${ }^{24-30}$ Human eye samples from patients with diabetic retinopathy and age-related macular degeneration exhibit elevated levels of NAEs, suggesting that they may be involved in an endogenous protective response
A

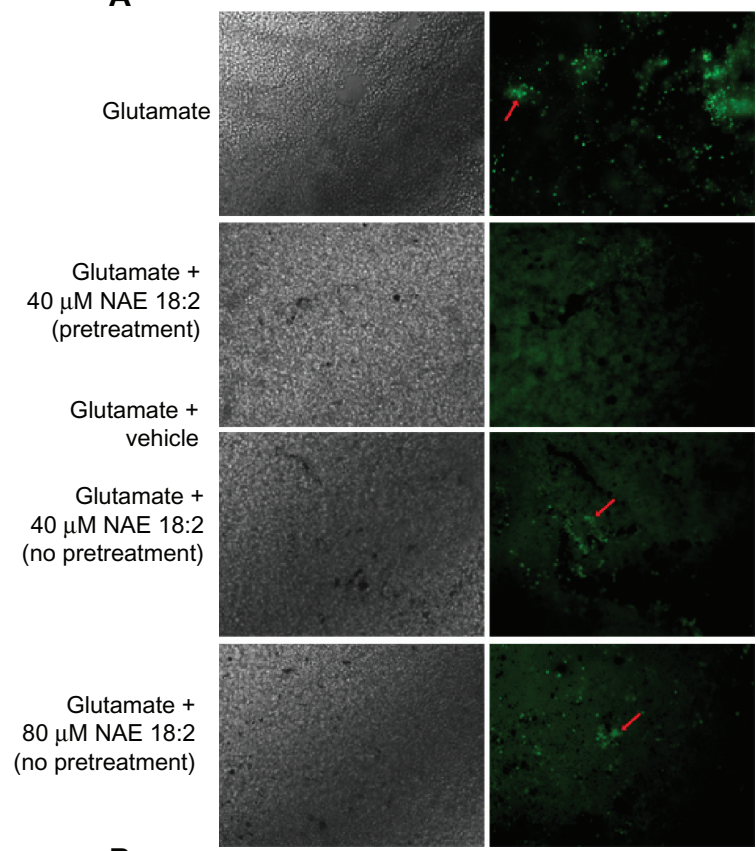

B

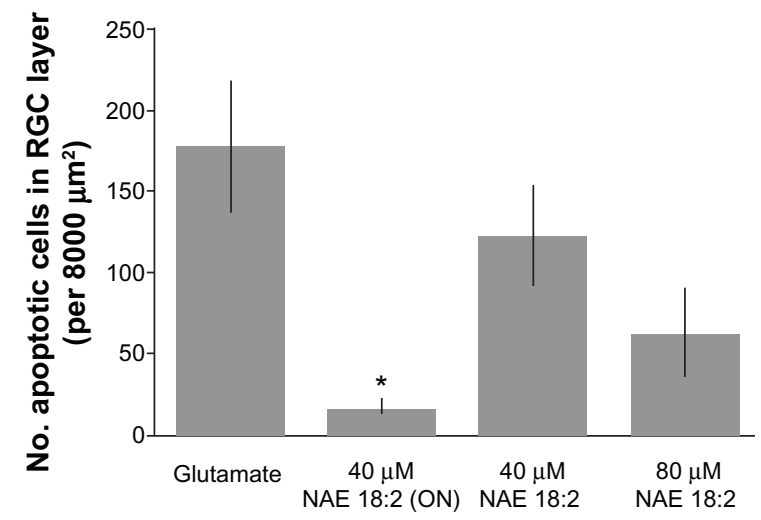

Figure 3 NAE 18:2 preincubation is required for protection of RGC layer neurons against glutamate excitotoxicity. NAE 18:2 preincubation is critical for its neuroprotective effect. A) Retina explants were either pretreated for 24 hours (ON) with $40 \mu \mathrm{M} N A E$ 18:2 prior to and during glutamate exposure or at the onset of glutamate exposure (no pretreatment). All glutamate exposures were for 24 hours, and NAE 18:2 was present during the glutamate exposure period. Note the lack of protection without pretreatment (red arrows). B) Quantitative summary data revealing the requirement for NAE 18:2 protection of RGC layer neurons against glutamate.

Notes: *denotes $P<0.05$, as determined by a one-way analysis of variance test. Scale bar: $50 \mu \mathrm{M}$.

Abbreviations: DIC, differential interference contrast; NAE, $N$-acylethanolamide; ON, overnight; RGC, retinal ganglion cell; TUNEL, terminal deoxynucleotidyl transferase-mediated dUTP (2'-deoxyuridine $5^{\prime}$-triphosphate) nick-end labeling green fluorescence.

to eye injury. ${ }^{35}$ Interestingly, high IOP-induced ischemia in rats results in reduced anandamide (NAE 20:4) levels due to elevated fatty acid amide hydrolase (FAAH) expression subsequently contributing to RGC loss..$^{36}$ This suggests that endocannabinoid NAEs are neuroprotective in the ischemic retina. This is further evidenced by improved RGC viability in the ischemic retina following pharmacological inhibition 
of FAAH. ${ }^{36}$ Altogether, data presented here and from others provide evidence for a neuroprotective role for NAEs against diseases of the retina such as glaucoma.

The neuroprotective mechanism of action of NAE 18:2 is not clear at this time. Others have proposed that NAE 18:2 is a vanilloid receptor 1 (VR1) agonist or that it reduces the degradation of the endocannabinoid NAE, NAE 20:4, by FAAH.${ }^{37,38}$ NAE 20:4 neuroprotection is mediated primarily through activation of $\mathrm{CB} 1$ and subsequent downregulation of cyclic adenosine monophosphate (cAMP) production and protein kinase A (PKA) activation. ${ }^{39,40}$ In addition, CB1 activation can inhibit voltage gated calcium channels, activate inward rectifying potassium channels, and activate various protein kinases. ${ }^{41-45}$ Most NAEs, including NAE 16:0 and NAE 18:2, do not activate cannabinoid receptors. ${ }^{46}$ Activation of VR1 leads to apoptosis in a variety of cell culture model systems, thus making VR1 activation an unlikely target for NAE 18:2 protective effects. ${ }^{47,48}$

We previously determined that, in the HT-22 neuronal cell line, NAE16:0 is neuroprotective against oxidative stress by a mechanism independent of cannabinoid receptor involvement and correlating with Akt and ERK1/2 activation. ${ }^{22}$ Furthermore, NAE 16:0 administration reduces infarct volume and improves behavioral deficits independent of CB1 or VR1 in a rat model of ischemic stroke. ${ }^{23} \mathrm{CB} 1$ is expressed in vascular smooth muscles of cerebral arteries. ${ }^{49}$ Peripheral CB1 activation by systemic administration of NAE 20:4 dilates cerebral arteries. ${ }^{50}$ Neuroprotection afforded by NAE 16:0 against ischemic stroke is not blocked by inhibitors of CB1 or VR1, suggesting that the protection is not due to cerebral vasodilation. ${ }^{23}$ The retina explant model used in the present study excludes any vasodilatative or hemodynamic mechanism of action for the neuroprotective effect of NAE 18:2 in the retina. The mechanism of action for NAE 18:2 neuroprotection is likely a direct effect on RGCs similar to that previously observed with other noncannabinoid NAEs in a neuronal cell line model. ${ }^{22}$

Altogether, the data presented here and from previous studies indicate that neuroprotection by some NAEs is independent of cannabinoid receptor activation and is mediated by an unknown mechanism. The diversity of NAEs and their potential functional targets may provide a variety of new therapeutic targets for the treatment of neurodegenerative diseases, including glaucomatous retinopathy.

\section{Grant support/acknowledgments}

This study was supported in part by grants EY014227 from NIH/NEI, RR022570, RR027093 from NIH/NCRR and AG010485, AG022550 and AG027956 from NIH/NIA, the
Vision Research Foundation of Kansas City and the Felix and Carmen Sabates Missouri Endowed Chair in Vision Research (P.K.). We thank Margaret, Richard and Sara Koulen for generous support and encouragement.

\section{Disclosure}

The authors report no conflicts of interest in this work.

\section{References}

1. Weinreb RN, Khaw PT. Primary open-angle glaucoma. Lancet. 2004; 363:1711-1720.

2. Yuan L, Neufeld AH. Tumor necrosis factor-alpha: a potentially neurodestructive cytokine produced by glia in the human glaucomatous optic nerve head. Glia. 2000;32:42-50.

3. Moreno MC, Campanelli J, Sande P, Sánez DA, Keller Sarmiento MI, Rosenstein RE. Retinal oxidative stress induced by high intraocular pressure. Free Radic Biol Med. 2004;37:803-812.

4. Seki M, Lipton SA. Targeting excitotoxic/free radical signaling pathways for therapeutic intervention in glaucoma. Prog Brain Res. 2008;173:495-510.

5. Hare WA, Wheeler L. Experimental glutamatergic excitotoxicity in rabbit retinal ganglion cells: block by memantine. Invest Ophthalmol Vis Sci. 2009;50:2940-2948.

6. Son JL, Soto I, Oglesby E, et al. Glaucomatous optic nerve injury involves early astrocyte reactivity and late oligodendrocyte loss. Glia. 2010;58:780-789.

7. Hahn JS, Aizenman E, Lipton SA. Central mammalian neurons normally resistant to glutamate toxicity are made sensitive by elevated extracellular Ca2+: toxicity is blocked by the N-methyl-D-aspartate antagonist MK-801. Proc Natl Acad Sci US A. 1988;85: 6556-6560.

8. Vorwerk CK, Lipton SA, Zurakowski D, Hyman BT, Sabel BA, Dreyer EB. Chronic low-dose glutamate is toxic to retinal ganglion cells. Toxicity blocked by memantine. Invest Ophthalmol Vis Sci. 1996;37: 1618-1624.

9. Otori Y, Wei JY, Barnstable CJ. Neurotoxic effects of low doses of glutamate on purified rat retinal ganglion cells. Invest Ophthalmol Vis Sci. 1998;39:972-981.

10. WoldeMussie E, Yoles E, Schwartz M, Ruiz G, Wheeler LA. Neuroprotective effect of memantine in different retinal injury models in rats. J Glaucoma. 2002;11:474 480.

11. Manabe $\mathrm{S}, \mathrm{Gu} Z$, Lipton SA. Activation of matrix metalloproteinase-9 via neuronal nitric oxide synthase contributes to NMDA-induced retinal ganglion cell death. Invest Ophthalmol Vis Sci. 2005;46:4747-4753.

12. Chidlow G, Wood JP, Casson RJ. Pharmacological neuroprotection for glaucoma. Drugs. 2007;67:725-759.

13. Osborne NN. Recent clinical findings with memantine should not mean that the idea of neuroprotection in glaucoma is abandoned. Acta Ophthalmol. 2009;87:450-454.

14. Sun Q, Ooi VE, Chan SO. N-methyl-D-aspartate-induced excitotoxicity in adult rat retina is antagonized by single systemic injection of MK- 801 . Exp Brain Res. 2001;138:37-45.

15. Xin H, Yannazzo JA, Duncan RS, Gregg EV, Singh M, Koulen P. A novel organotypic culture model of the postnatal mouse retina allows the study of glutamate-mediated excitotoxicity. J Neurosci Methods. 2007; 159:35-42.

16. Epps DE, Schmid PC, Natarajan V, Schmid HH. N-Acylethanolamine accumulation in infarcted myocardium. Biochem Biophys Res Commun. 1979;90:628-633.

17. Epps DE, Natarajan V, Schmid PC, Schmid HO. Accumulation of N-acylethanolamine glycerophospholipids in infarcted myocardium. Biochim Biophys Acta. 1980;618:420-430.

18. Natarajan V, Schmid PC, Schmid HH. N-acylethanolamine phospholipid metabolism in normal and ischemic rat brain. Biochim Biophys Acta. $1986 ; 878: 32-41$. 
19. Hansen HS, Lauritzen L, Strand AM, Moesgaard B, Frandsen A. Glutamate stimulates the formation of $\mathrm{N}$-acylphosphatidylethanolamine and $\mathrm{N}$-acylethanolamine in cortical neurons in culture. Biochim Biophys Acta. 1995;1258:303-308.

20. Moesgaard B, Jaroszewski JW, Hansen HS. Accumulation of $\mathrm{N}$-acyl-ethanolamine phospholipids in rat brains during post-decapitative ischemia: a 31p NMR study. J Lipid Res. 1999;40:515-521.

21. Schäbitz WR, Giuffrida A, Berger C, et al. Release of fatty acid amides in a patient with hemispheric stroke: a microdialysis study. Stroke. 2002;33:2112-2114.

22. Duncan RS, Chapman KD, Koulen P. The neuroprotective properties of palmitoylethanolamine against oxidative stress in a neuronal cell line. Mol Neurodegener. 2009;4:50.

23. Garg P, Duncan RS, Kaja S, Koulen P. Intracellular mechanisms of $\mathrm{N}$-acylethanolamine-mediated neuroprotection in a rat model of stroke. Neuroscience. 2010;166:252-262.

24. Chen J, Matias I, Dinh T, et al. Finding of endocannabinoids in human eye tissues: implications for glaucoma. Biochem Biophys Res Commun. 2005;330:1062-1067.

25. Straiker AJ, Maguire G, Mackie K, Lindsey J. Localization of cannabinoid CB1 receptors in the human anterior eye and retina. Invest Ophthalmol Vis Sci. 1999;40:2442-2448.

26. Yazulla S, Studholme KM, McIntosh HH, Deutsch DG. Immunocytochemical localization of cannabinoid CB1 receptor and fatty acid amide hydrolase in rat retina. J Comp Neurol. 1999;415:80-90.

27. Lu Q, Straiker A, Lu Q, Maguire G. Expression of CB2 cannabinoid receptor mRNA in adult rat retina. Vis Neurosci. 2000;17:91-95.

28. Glaser ST, Deutsch DG, Studholme KM, Zimov S, Yazulla S. Endocannabinoids in the intact retina: $3 \mathrm{H}$-anandamide uptake, fatty acid amide hydrolase immunoreactivity and hydrolysis of anandamide. Vis Neurosci. 2005;22:693-705.

29. Zimov S, Yazulla S. Vanilloid receptor 1 (TRPV1/VR1) co-localizes with fatty acid amide hydrolase (FAAH) in retinal amacrine cells. Vis Neurosci. 2007;24:581-591

30. Hu SS, Arnold A, Hutchens JM, Radicke J, et al. Architecture of cannabinoid signaling in mouse retina. J Comp Neurol. 2010;518: 3848-3866.

31. El-Remessy AB, Khalil IE, Matragoon S, et al. Neuroprotective effect of (-) Delta9-tetrahydrocannabinol and cannabidiol in N-methyl-Daspartate-induced retinal neurotoxicity: involvement of peroxynitrite. Am J Pathol. 2003;163:1997-2008.

32. Mafe OA, Gregg EV, Medina-Ortiz WE, Koulen P. Localization of inositol 1,4,5-trisphosphate receptors in mouse retinal ganglion cells. J Neurosci Res. 2006;84:1750-1758.

33. Ullian EM, Barkis WB, Chen S, Diamond JS, Barres BA. Invulnerability of retinal ganglion cells to NMDA excitotoxicity. Mol Cell Neurosci. 2004;26:544-557.

34. Wamsley S, Gabelt BT, Dahl DB, et al. Vitreous glutamate concentration and axon loss in monkeys with experimental glaucoma. Arch Ophthalmol. 2005;123:64-70.
35. Matias I, Wang JW, Moriello AS, Nieves A, Woodward DF, Di Marzo V. Changes in endocannabinoid and palmitoylethanolamide levels in eye tissues of patients with diabetic retinopathy and age-related macular degeneration. Prostaglandins Leukot Essent Fatty Acids. 2006;75:413-418.

36. Nucci C, Gasperi V, Tartaglione R, et al. Involvement of the endocannabinoid system in retinal damage after high intraocular pressure-induced ischemia in rats. Invest Ophthalmol Vis Sci. 2007;48:2997-3004.

37. Jonsson KO, Vandevoorde S, Lambert DM, Tiger G, Fowler CJ. Effects of homologues and analogues of palmitoylethanolamide upon the inactivation of the endocannabinoid anandamide. Br J Pharmacol. 2001;133:1263-1275

38. Movahed P, Jönsson BA, Birnir B, et al. Endogenous unsaturated $\mathrm{C} 18 \mathrm{~N}$-acylethanolamines are vanilloid receptor (TRPV1) agonists. J Biol Chem. 2005;280:38496-38504.

39. Howlett AC, Qualy JM, Khachatrian LL. Involvement of Gi in the inhibition of adenylate cyclase by cannabimimetic drugs. Mol Pharmacol. 1986;29:307-313.

40. Devane WA, Dysarz FA 3rd, Johnson MR, Melvin LS, Howlett AC. Determination and characterization of a cannabinoid receptor in rat brain. Mol Pharmacol. 1988;34:605-613.

41. Mackie K, Hille B. Cannabinoids inhibit N-type calcium channels in neuroblastoma-glioma cells. Proc Natl Acad Sci U SA. 1992;89:3825-3829.

42. Bouaboula M, Poinot-Chazel C, Bourrié B, et al. Activation of mitogenactivated protein kinases by stimulation of the central cannabinoid receptor CB1. Biochem J. 1995;312:637-641.

43. Henry DJ, Chavkin C. Activation of inwardly rectifying potassium channels (GIRK1) by co-expressed rat brain cannabinoid receptors in Xenopus oocytes. Neurosci Lett. 1995;186:91-94.

44. Derkinderen P, Toutant M, Burgaya F, et al. Regulation of a neuronal form of focal adhesion kinase by anandamide. Science. 1996;273: 1719-1722.

45. Derkinderen P, Ledent C, Parmentier M, Girault JA. Cannabinoids activate p38 mitogen-activated protein kinases through CB1 receptors in hippocampus. J Neurochem. 2001;77:957-960.

46. Lambert DM, Di Marzo V. The palmitoylethanolamide and oleamide enigmas: are these two fatty acid amides cannabimimetic? Curr Med Chem. 1999;6:757-773.

47. Maccarrone M, Lorenzon T, Bari M, Melino G, Finazzi-Agro A. Anandamide induces apoptosis in human cells via vanilloid receptors. Evidence for a protective role of cannabinoid receptors. J Biol Chem. 2000;275:31938-31945.

48. Shirakawa H, Yamaoka T, Sanpei K, Sasaoka H, Nakagawa T, Kaneko S. TRPV1 stimulation triggers apoptotic cell death of rat cortical neurons. Biochem Biophys Res Commun. 2008;377:1211-1215.

49. Ashton JC, Appleton I, Darlington CL, Smith PF. Immunohistochemical localization of cerebrovascular cannabinoid CB1 receptor protein. J Cardiovasc Pharmacol. 2004;44:517-519.

50. Wagner JA, Járai Z, Bátkai S, Kunos G. Hemodynamic effects of cannabinoids: coronary and cerebral vasodilation mediated by cannabinoid CB(1) receptors. Eur J Pharmacol. 2001;423:203-210.
Clinical Ophthalmology

\section{Publish your work in this journal}

Clinical Ophthalmology is an international, peer-reviewed journal covering all subspecialties within ophthalmology. Key topics include: Optometry; Visual science; Pharmacology and drug therapy in eye diseases; Basic Sciences; Primary and Secondary eye care; Patient Safety and Quality of Care Improvements. This journal is indexed on Submit your manuscript here: http://www.dovepress.com/clinical-ophthalmology-journal

\section{Dovepress}

PubMed Central and CAS, and is the official journal of The Society of Clinical Ophthalmology (SCO). The manuscript management system is completely online and includes a very quick and fair peer-review system, which is all easy to use. Visit http://www.dovepress.com/ testimonials.php to read real quotes from published authors. 